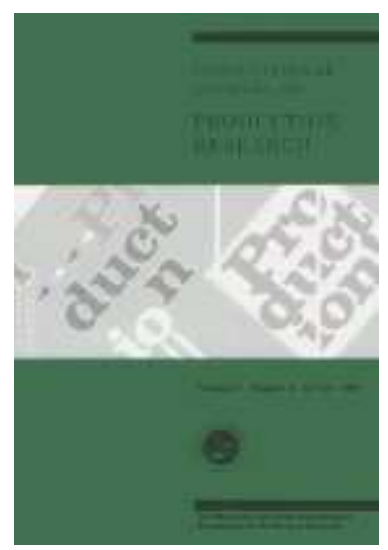

\title{
A RULE-BASED MULTI-CRITERIA APPROACH TO INVENTORY CLASSIFICATION
}

\begin{tabular}{|r|l|}
\hline Journal: & International Journal of Production Research \\
\hline Manuscript ID: & TPRS-2009-IJPR-0571.R1 \\
\hline Manuscript Type: & Original Manuscript \\
\hline Author: & $10-$ Sep-2009 \\
\hline Complete List of Authors: & $\begin{array}{l}\text { Rezaei, Jafar; Delft University of Technology, Faculty of Technology, } \\
\text { Policy and Management, Section Technology, Strategy \& } \\
\text { Entrepreneurship } \\
\text { Dowlatshahi, S; The University of Missouri - Kansas City, HW Bloch } \\
\text { School of Business and Public Admin }\end{array}$ \\
\hline Keywords: & $\begin{array}{l}\text { INVENTORY MANAGEMENT, MULTI-CRITERIA DECISION MAKING, } \\
\text { FUZZY LOGIC }\end{array}$ \\
\hline Keywords (user): & ABC CLASSIFICATION, FUZZY INFERENCE SYSTEM \\
\hline \multicolumn{2}{|l}{} \\
\hline
\end{tabular}

\section{ScholarONE" \\ Manuscript Central}




\title{
A RULE-BASED MULTI-CRITERIA APPROACH TO INVENTORY CLASSIFICATION
}

\author{
Jafar Rezaei $^{\mathrm{a}}$, Shad Dowlatshahi ${ }^{\mathrm{b}}$ \\ ${ }^{a} \mathrm{PhD}$ Student, Section Technology, Strategy and Entrepreneurship \\ Faculty of Technology, Policy and Management, Delft University of Technology \\ P.O. Box 5015, 2600 GA Delft, The Netherlands \\ Phone: +31 152782985 \\ Fax: +31 152783177 \\ j.rezaei@tudelft.nl \\ ${ }^{b}$ Professor of Operations Management \\ Division of Business Administration \\ HW Bloch School of Business and Public Administration \\ The University of Missouri-Kansas City \\ 5110 Cherry \\ Kansas City, MO 64110-2499, USA \\ Phone: (816) 235-2233 \\ Fax: (816) 235-6506 \\ shad@umkc.edu
}




\title{
A RULE-BASED MULTI-CRITERIA APPROACH TO INVENTORY CLASSIFICATION
}

\begin{abstract}
The traditional inventory classification method classifies Stock Keeping Units (SKUs) to three classes based on their annual dollar usage, while in real world problems, other criteria are important as well. In this paper, considering multi-criteria situations, a simple, effective and practical rule-based method is designed and implemented in a real world case, using the MATLAB software. The most important characteristic of the proposed method is taking into account the inherent ambiguities that exist in the reasoning process of the system of classification. The methodology and the method proposed here may be easily implemented by inventory managers. The results obtained from the case study in this paper are compared with Analytic Hierarchy Process (AHP) method. Finally concluding remarks and suggestion for future work are provided.
\end{abstract}

Keyword: inventory management, ABC classification, multi-criteria decision-making, fuzzy logic, and fuzzy inference system. 


\section{Introduction}

The $\mathrm{ABC}$ inventory classification process is an analysis of a range of distinct items, referred to as Stock Keeping Units (SKUs), such as finished products into three categories: A outstandingly important; B -of average importance; C -relatively unimportant as a basis for an inventory control scheme. Each category can and sometimes should be handled in a different way, with more attention being devoted to category A, less to B, and even lesser to $\mathrm{C}$. The larger firms, with larger inventory investments, will often use a 12-class system (Martin, 2007).

The traditional ABC classification has generally been based on just one criterion -the annual dollar usage of the items. However depending on what part of the organization is concerned; the criterion of what is most important with respect to inventory items can change (Flores and Whybark, 1986). There are other criteria that represent important considerations for management such as lead time, obsolescence, availability, substitutability, criticality, repairability, commonality, certainty of supply, impact of stock out, inventory cost, number of requests for the item in a year, scarcity, durability, order size requirement, stock ability, and demand distribution (Flores and Whybark, 1986, 1987; Ramanathan, 2006; Rezaei, 2007; Vollman et al., 1997).

In this paper using fuzzy logic developed by Zadeh (1965) a simple and applicable method for multi-criteria inventory classification is presented. The remainder of this paper is structured in four sections. This introduction is followed by a literature review. Sections 2 presents the research methodology. The case study and comparisons and assessment of the results are discussed in section 3. Finally conclusions of the results and future research directions are provided in section 4 .

\section{$\underline{1.1 \text { Review of literature }}$}

Multi-criteria Inventory Classification (MCIC) has been introduced by Flores and Whybark (Flores and Whybark, 1986, 1987). Although they introduced several criteria such as obsolescence, lead times, substitutability, repairability, criticality and commonality, their concept of a 'joint criteria matrix' was developed for two criteria. This concept is not a suitable method for considering more than two criteria. They stated "the greater the number of criteria that are viewed as important, the more complex the task of developing the classification becomes. If all criteria are important and need to be incorporated in the analysis, the task may be very hard" (Flores and Whybark, 1986). The 'joint criteria matrix', therefore, can be considered as a bi- 
criteria inventory classification. However based on the authors' multi-criteria concept, several multi-criteria decision-making (MCDM) methods have been proposed to solve this problem.

Cohen and Ernst (1988) used a statistical technique called cluster analysis to group items across many dimensions. The main advantage of this approach is that it can accommodate large number of combination of attributes, which are significant for both strategic and operational reasons. However, this requires substantial data and the use of factor analysis and a clustering procedure may render this technique impractical in typical stockroom environment. Furthermore the clusters themselves must be re-evaluated in order to classify new stock items. Therefore, there is a chance that previously classified stock may end up being re-classified differently every time new items are added. This may disturb the inventory control procedure. In short, their method may be too sophisticated for the average manager (Partovi and Anandarajan, 2002).

Flores et al. (1992) and Partovi and Burton (1993) presented similar approaches to the ABC classification problem. The proposed methods based on Saaty's Analytic Hierarchy Process (AHP) (Saaty, 1982), rated items on both qualitative and quantitative criteria. The main advantage of the AHP method is that it is able to consider several criteria. However, when the number of criteria is increased, the consistency rate will be very sensitive and reaching to a consistent rate will be very difficult.

Reynolds (1994) provided a classification scheme, appropriate for process industries. This classification assisted managers to focus their attention on important items even if they are rarely used. However the application of this method may not be suitable in other industries.

Guvenir and Erel (1998) proposed a method to learn the weight vector along with the cut-off values for multi-criteria inventory classification. The proposed method called Genetic Algorithm for Multi-criteria Inventory Classification (GAMIC) used a genetic algorithm to learn the weights of criteria along with $\mathrm{AB}$ and $\mathrm{BC}$ cut-off points from pre classified items. Once the criteria weights are obtained, the weighted scores of the items in the inventory are computed similarly to the approach with AHP. Then the items with scores greater than AB cut-off value are classified as class $\mathrm{A}$; those with scores between $\mathrm{AB}$ and $\mathrm{BC}$ as class $\mathrm{B}$; and the remaining items are classified as class C. This method had the advantages and disadvantages of AHP method. In addition, the classification results, to some extent, depended on the pre-classified items.

Puente et al. (2002) presented a fuzzy method of classifying different productive items of a company. Whereas the rankings obtained using the classical method were based on information 
about costs and demand over a period of time in the past. This new method allowed new fuzzy information about the future to be included, thus allowing stricter control of the fuzzy 'A-items' that resulted from this new classification. The authors, however, only considered two criteria of demand and cost in their study. The authors' model was in fact a bi-criteria rather than a multicriteria model.

Partovi and Anandarajan (2002) presented an artificial neural network for ABC classification of inventory. They utilized two learning methods in their approach: back propagation and genetic algorithm. The reliability of their proposed methods was tested by comparing their classification ability with two data sets. The methods were compared with the multiple Discriminant Analysis technique. Their results showed that both proposed methods had higher predictive accuracy than Discriminant Analysis. There was no significant difference between the two learning methods used to develop the artificial neural network. However the application of these methods is difficult for an average inventory manager.

Ramanathan (2006) proposed a weighted linear optimization method for classifying inventory items with multiple criteria. In the proposed approach, a weighted additive function was used to aggregate the performance of an inventory item in terms of different criteria to a single score, called the optimal inventory score of an item. The weights were chosen using optimization method subject to the constraints that the weighted sum for all the items must be less than or equal to one. The weighted sum was computed using the same set of weights. This method used a maximization objective function. To obtain the optimal scores of all inventory items, proposed method should be solved repeatedly by changing the objective function. These scores can then be used to classify the inventory items. Zhou and Fan (2007) presented an extended version of the Ramanathan's model. They incorporated some balancing features for MCIC using two sets of weights that are most favorable and least favorable for each item.

Rezaei (2007), by using Fuzzy Analytic Hierarchy Process (FAHP), presented a MCIC method. The weights of the criteria were calculated by using FAHP; then a six-step algorithm was presented to calculate the final normalized weighted score of each item. Finally, using a principle of comparison for fuzzy numbers, the final scores were compared with one another and all items were classified into three classes according to their final scores. Cakir and Canbolat (2008) presented a methodology for MCIC by using FAHP as well. The difference of this 
method and Rezaei (2007) method was that this method was web-based and used a decision support system.

Bhattacharya et al. (2007) using the TOPSIS (Technique for Order Preferences by Similarity to the Ideal Solution) proposed a Multi Attribute Inventory Classification (MAIC) method. They illustrated this technique in a pharmaceutical company by considering these criteria unit cost, lead time, consumption rate, perishability of items and cost of storing of raw materials in a crisp format. They concluded that constructing fuzzy models such as fuzzy TOPSIS and neuro-fuzzy hybrid model would be suitable by taking the vagueness in attribute values into account.

Chu et al. (2008) proposed an inventory control approach combining ABC and fuzzy classification. They applied this method to an example with 159 SKUs and surprisingly classified 59 items in class A, 69 items in class B and 64 items in class C which is not consistent with the basic concept of ABC classification. However it does not seem logical to classify roughly the same number of SKUs at three classes A, B and C.

Chen et al. (2008) introduced a case-based MCIC based on the 'right' distance based preference expression. Using the decision-maker's assessment of case sets as input, preferences over alternatives were represented intuitively by using weighted Euclidean distances. Then a quadratic optimization program finds optimal classification thresholds. Although this method is a robust one, this method requires some complicated implementation steps which may confuse the decision-maker. This method classified items to just three classes and for the cases requiring more than three classes the complication of the method will be dramatically increased.

\subsection{The implications and assessment of the literature review}

Table 1 provides an overview of the literature review and the methods used therein.

\section{TABLE 1 GOES ABOUT HERE}

The literature review revealed that a large number of MCDM techniques have been applied to inventory classification problems. However, only three of these references (Cakir and Canbolat, 2008; Rezaei, 2007; Puente et al., 2002) have considered the inventory classification problem in a fuzzy sense. In fact the proposed model in (Puente et al., 2002) is a limited bi- 
criteria model in which only two criteria work in the fuzzy environment. Both of the other works (Cakir and Canbolat, 2008; Rezaei, 2007) applied fuzzy AHP.

The advantages and disadvantages of various methods to inventory classification were explored in the literature review. Also, as mentioned by Zadeh (1996) humans employ mostly words in 'computing' and 'reasoning'. Fuzzy AHP makes the problem closer to the real world by using words (and equivalent fuzzy numbers) in computing, but it does not apply words in reasoning. Fuzzy logic enables us to use words (or natural language) for both computing and reasoning. Therefore considering the inherent vagueness in measuring the relevant criteria in most real world situations, applying fuzzy logic is a more suitable and logical approach. Additionally this approach is capable of handling both quantitative and qualitative criteria. Also, as the output of this method is a set of defuzzified scores in the range 0 to 1 , the decisionmaker can classify the SKUs to a desired number of classes. In other words, the decision-maker determines the cut-off points. As constructing the rules is independent from the characteristics of each specific SKU, to classify the new SKUs, no change is necessary in the rule base. Although in most real world situations choosing a limited number of criteria is important for inventory classification purposes, this approach has the ability to consider a large number of criteria. In this case one may think that the number of rules could be increased exponentially. In order to avoid this possible case, we can use the 'rule base reduction' methods (see for example Setnes et al., 1998; Yam et al., 1999).

Precise data and weighting factors usually are not always available in practical situations. The criteria that affect $\mathrm{ABC}$ classification are not independent. Volumes of demand, for example, have a large impact on lead times. Bearing this in mind, managers prefer linguistic to numerical values in measuring criteria affecting $\mathrm{ABC}$ classification. In many cases, researchers have utilized natural language expressions such as high, low, or fair in their attempt to evaluate these factors. Generally, the representation of managerial knowledge by linguistic rules performs better when there are no units of measurement for the attributes of the system and no quantitative criteria for the values of such attributes (Zadeh, 1983). Fuzzy logic offers a systematic base in dealing with such cases.

\section{Methodology}


Motivated by the ideas about fuzzy logic, we introduce a rule-based measurement scheme for MCIC. The most important characteristic of the proposed method is taking into account the inherent ambiguities that exist in the reasoning process of the system of classification. Rules contain already known facts but in compact form, such as, 'IF durability is low, and ... THEN the item belongs to class $\mathrm{A}^{\prime}$ in which the linguistic value (low) here is represented by the appropriate fuzzy set. The class of item is the result of a fuzzy or approximate reasoning procedure.

\section{$\underline{2.1 \text { Fuzzy Inference Systems }}$}

Fuzzy inference systems are also known as fuzzy-rule-based systems, fuzzy models, fuzzy associative memories (FAM), or fuzzy controllers when used as controllers. Basically a fuzzy inference system is composed of five functional blocks as described in Fig. 1 by Jang (1993):

- a rule base containing a number of fuzzy IF - THEN rules;

- a database which defines the membership functions of the fuzzy sets used in the fuzzy rules;

- a decision-making unit which performs the inference operations on the rules;

- a fuzzification interface which transforms the crisp inputs into degrees of match with linguistic values;

- a defuzzification interface, which transform the fuzzy results of the inference into a crisp output.

Usually, the rule base and the database are jointly referred to as the knowledge base.

\section{FIGURE 1 GOES ABOUT HERE}

\subsubsection{Fuzzification inference}

Fig. 2 illustrates the intended fuzzy inference system in which we define four input linguistic variables for each inventory item. They are Unit Price (UP), Annual Demand (AD), Lead Time (LT), and Durability (DU). These criteria were selected by the inventory managers of the company selected for this study. In this case to fuzzify the input and output variables, using the expert's knowledge, the following fuzzy subsets (linguistic values) are used: Low (L); with corresponding fuzzy number: $(0,0,0.4)$, Medium $(\mathrm{M})$; with corresponding fuzzy number: $(0.1$, $0.5,0.9)$, and High $(\mathrm{H})$; with corresponding fuzzy number: $(0.6,1,1)$. These subsets are known as triangular membership functions. If $F$ be a triangular fuzzy number in $R$ and $a, b, c, x \in R$, its membership function $\mu_{F}: R \rightarrow[0,1]$ is: 


$$
\mu_{F}(x)=\left\{\begin{array}{lc}
(x-a) /(b-a), & a \leq x \leq b, \\
(c-x) /(c-b), & b \leq x \leq c, \\
0, & \text { otherwise. }
\end{array}\right.
$$

It should be noted that the linguistic values are commonly used by all variables but they are scaled into the interval $[0,1]$ (see equations (4) and (5) in section 3 ). The physical domain of the linguistic variables is defined by managers. For example, the physical domain of LT in this paper is $[1,7]$ days.

\section{FIGURE 2 GOES ABOUT HERE}

\subsubsection{Knowledge base}

As mentioned before, the rule base and the database are jointly referred to as the knowledge base. The knowledge acquisition phase comprises experts' knowledge of the application domain and the decision rules that govern the relationships between inputs and outputs. The membership functions of inputs and outputs are designed by inventory managers of the company studied based on their knowledge of the system and their experience. However, the main purpose of the knowledge base is to provide a fuzzy rule base needed for the fuzzy processor.

\subsubsection{Fuzzy rule base}

The fuzzy rule base contains a set of IF-THEN rules developed by the experience and knowledge of one or more experts. A typical fuzzy rule has the form: IF antecedent THEN consequent. The rule base of our study contains $3^{4}=81$ rules, which include all variations of the linguistic values, i.e., three linguistic values for each of the four linguistic variables. The rules were constructed based on inventory managers' knowledge. The rules representing these experts' knowledge showing how the variables affect classification have the following form:

\begin{tabular}{|clcc|}
\hline IF & unit price & is & $u p \in U P$ \\
AND & annual demand & is & $a d \in A D$ \\
AND & lead time & is & $l t \in L T$ \\
AND & durability & is & $d u \in D U$ \\
THEN & item class & is & $i c \in I C$ \\
& & & \\
\hline
\end{tabular}

Let $\mathrm{T}=\{\mathrm{L}, \mathrm{M}, \mathrm{H}\}$ be the set of linguistic values for all the five input and output variables $\mathrm{UP}, \mathrm{AD}, \mathrm{LT}$, DU and IC, and let $T_{U P}, T_{A D}, T_{L T}, T_{D U}$ and $T_{I C} \in T$ be the linguistic value sets for UP, AD, LT, DU and IC respectively. Then the above rule can be re-written compactly as follows: 
IF UP is $T_{U P}$ AND AD is $T_{A D}$ AND LT is $T_{L T}$ AND DU is $T_{D U}$ THEN IC is $T_{I C}$ where $T_{U P}, T_{A D}, T_{L T}, T_{D U}$ and $T_{I C} \in T$.

Table 2 shows a sample of the developed rule base (with four inputs).

\section{TABLE 2 GOES ABOUT HERE}

\subsubsection{Decision-making unit}

The decision-making unit, also known as fuzzy inference engine, is similar to simulating human decision-making in inferring fuzzy control actions based on the rules of inference in fuzzy logic. The evaluation of a rule is based on computing the truth value of its premise part and applying it to its conclusion part. This results in assigning one fuzzy subset to each output variable of the rule. This component interacts with the knowledge base and performs mathematical computations based on the above fuzzy numbers. In particular, they take place according to mathematical operators that are defined, on the basis of the expert's knowledge, for the connectives AND/OR, ELSE and the IF/THEN implication. In this paper, the type of inference engine developed by Mamadani and Assilian (1975) was used by employing a compositional minimum operator, which represents a conservative attitude towards $\mathrm{ABC}$ classification (see Fig. 2). In minimum inferencing the entire strength of the rule is considered as the minimum membership value of the input variables' membership values.

$\mu_{\text {output }}=\min \left\{\mu_{\text {input } 1}, \mu_{\text {input } 2}, \cdots, \mu_{\text {input } N}\right\}$

\subsubsection{The defuzzification interface}

The output of fuzzy inference engine is a fuzzy number while decision-maker needs a crisp number. Defuzzification inference is the final operation that converts this fuzzy output into a crisp output. In general, there are five methods of defuzzification described in the literature (Yen and Langari, 1999). These include the Center of Gravity (COG) defuzzification or the Mean of Maximum (MOM) defuzzification. The COG is the one that is most commonly used. This technique calculates the centre of the area of the combined membership function as:

$$
y_{0}=\frac{\int_{i} \mu_{F}\left(y_{i}\right) y_{i} d y_{i}}{\int_{i} \mu_{F}\left(y_{i}\right) d y_{i}}
$$


where $y_{i}$ is the representative value of the fuzzy subset member $i$ of the output, and $\mu_{F}\left(y_{i}\right)$ is the confidence in that member (membership value) and $y_{0}$ is the crisp value of the output.

\section{The case study}

The proposed methodology has been applied to the case study of a food manufacturing company (XYZ Company). XYZ is a medium-sized company that produces cooking and table margarines. The majority of XYZ's products are sold and consumed in The Netherlands, Belgium, France, and Germany. XYZ produces 13 product families (170 products under five brands). The number of XYZ's SKUs (including raw materials, work-in-process goods and completely finished goods and MRO -Maintenance, Repair, and Operations- goods) is more than 4200. To build a fuzzy expert system for an inventory classification method that is based on fuzzy logic, the researchers have captured, organized and used human expert knowledge by interviewing the inventory managers.

Today food manufacturers are struggling in a very competitive environment, especially for the highly perishable products. The selection of a food manufacturer is a good case study because it uses perishable materials. Other criteria such as durability, lead time, etc. would become important as well. The only two criteria of annual demand and unit price that are typically considered in traditional inventory classification would not work for food manufacturers.

For our study we choose a sample of 54 SKUs denoted as S1 through S54 (see Table 3, presented in Appendix I). As the XYZ's inventory managers were familiar with the inventory classification, we requested them to carefully select a sample of SKUs that would be a suitable representative of all SKUs of the company.

Four criteria of UP, AD, LT, and DU based on the degree of their importance as indicated by company inventory managers through personal interviews were used. The first three criteria were positively related to the score of the inventory items, while the DU had a negative relationship with the score of the inventory items. Table 3 (presented in Appendix I) shows the original and normalized measures (columns 2-9). By normalizing the UP, AD, and LT criteria measures using equation (4) and the DU criterion measure using equation (5) in the scale of 0-1.

$$
F_{\text {pos }}^{\text {norm }}=\frac{F_{i}-F_{\min }}{F_{\max }-F_{\min }}
$$




$$
F_{\text {neg }}^{\text {norm }}=\frac{F_{\max }-F_{i}}{F_{\text {max }}-F_{\text {min }}}
$$

where $F_{i}, F_{\max }$ and $F_{\min }$ are the $i$ th value, the maximum value, and the minimum value of the factor under normalization.

Using proposed methodology by MATLAB's Fuzzy Logic Toolbox (Jang and Gulley, 1995; MathWorks), defuzzified value for each item is calculated. For example consider item 1 (in Table 3). Normalized inputs for this item are: 0.387 (UP), 0.548 (AD), 0.5 (LT) and 0.706 (DU). After entering these values into the system (as shown at the bottom of Fig. 3) and based on their fuzzy sets, the decision rules are applied and the fuzzy results of the output variable IC are composed and defuzzified using the COG method, (see equation 3). Then the final output (defuzzified number) is calculated to be 0.553 . Table 3 (column 11) shows these results for all 54 SKUs.

Finally, the resulted defuzzified values are sorted in the descending order and the inventory classification is conducted based on the traditional ABC principle. The cut-off points determined based on the inventory managers' point of view. Therefore, we classify 9 SKUs of the top list (approximately 16\%) in class A, next 15 SKUs (approximately 28\%) in class B, and the last 30 SKUs (approximately 56\%) in class C (see Table 4, presented in Appendix II).

Here is the decision process a manager needs to follow when he or she decides to apply the proposed methodology:

1. Determine the most important criteria for the SKUs classification;

2. Make the IF-THEN rules in the MATLAB software;

3. Enter the measures of each item in the system. The output would be the defuzzified score for each item;

4. Sort the SKUs in the descending order and determine the cut-off points based on the desired number of classes. For example for three classes, determine two cut-off points.

\section{FIGURE 3 GOES ABOUT HERE}

\subsection{Comparisons of the results}

AHP is one of the most common techniques to solve MCDM problems in general and it is also a dominant technique in MCIC (see Flores et al., 1992; Partovi and Burton, 1993; Guvenir and Erel, 1998 for AHP, and Rezaei, 2007; Cakir and Canbolat, 2008 for fuzzy AHP). For comparison purposes, we have applied AHP method to the case data. Similar to the proposed 
methodology in this paper, AHP is constructed based on the user judgment and would be a suitable technique for our comparison purpose.

As the objective of this paper is not the application of the AHP method, we only report the scores that we have obtained for the criteria based on the judgment of the company inventory managers. For this case study the resulted weights are: 0.157 (UP), 0.41 (AD), 0.056 (LT), and 0.377 (DU). These values are used to calculate the score of each item. The AHP score of items can be seen in Table 3 (column 10). We sorted these scores in the descending order and classified the items to three classes (see Table 4, presented in Appendix II). We also adopted the number of items used in our proposed classification method.

Table 5 shows the comparison of the results of the proposed classification method with the AHP results. This comparison shows that:

- There are two cases of different classification of SKUs in class A.

- There are four cases of different classifications of SKUs in class B.

- There are four cases of different classifications of SKUs in class C.

\section{TABLE 5 GOES ABOUT HERE}

\subsection{Assessment of the results and discussion}

Herein we discuss the advantages of the proposed approach in comparison to AHP in classification of inventory.

The proposed rule-based method is completely constructed based on the inventory managers' reasoning. Using the proposed method, the inherent interdependencies between criteria are implicitly considered (in the phase of rule making). However the AHP is not capable of taking these interdependencies into account. For instance, it is expected that SKUs with low durability have relatively shorter lead time than more durable SKUs. Therefore, although both approaches are based on the managers' judgment, the proposed method results in more accurate and reliable classification.

In this paper, we have four criteria and 54 items. The final score of each item in the AHP is calculated by the sum of the product of item measures by criteria weight. The criteria weights are calculated based on a four by four pair-wise comparison matrix; while the final score of each item in the proposed method is based on 81 rules. Although both methods, as most MCDM methods, depend on experts knowledge and judgment, changing a few rules in the proposed method has a little impact on the final classification, while changing even one cell of pair-wise 
comparison matrix in the AHP may dramatically change the final classification. In AHP changing a cell results in changing all weights and consequently the final score of all alternatives (here SKUs). In rule-based system, the antecedents (IF ...) are pre-defined and the Decision Maker (DM) decides about the consequences (THEN ...). Changing one consequence only affects the final score of SKUs, which follow the antecedents of that specific rule (and not final score of all SKUs). Since the occurrence of errors in conducting the pair-wise comparison matrix or IF-THEN rules, in practical situations, is expected, the proposed method can become more suitable and less vulnerable than AHP.

In AHP the weights of criteria are determined based on a pair-wise comparison. In a pairwise comparison, the DM has to determine the preference of a criterion over another criterion in absence of the other criteria. In most real-world situations, however, the preference of a criterion over another one depends on other criteria. For example, if we ask the DM to assign a value between 1 and 9 to show his/her preference of Unit Price over Lead Time, he/she may state that this decision is dependent upon Durability. The DM may believe that 'if' the SKU is durable then Unit Price is preferred over Lead Time; otherwise Lead Time is preferred. If the DM believes that other criteria can influence his/her preference, this comparison will be become conditional depending on the number of other criteria. However AHP is not capable of considering the potential influence of other criteria on each pair-wise comparison. The proposed rule-based, however, is completely capable of considering this issue, as in each rule a specific combination of the importance of criteria is considered.

The final score of each item in AHP is calculated by the sum of the product of item measures by criteria weights. In other words, the final score of each item is obtained by a linear function. Therefore a change in each measure has a linear impact on final scores in AHP. However in some real-world situations changing a measure may have an exponential impact on the final score. This issue can be mitigated by the proposed method in the phase of rule-building.

Additionally, there have been some other serious concerns raised about the theoretical basis underlying the AHP. Harker and Vargas (1987) challenged the AHP and expressed four areas of concerns as follows: 1. lack of an axiomatic foundation, 2. the ambiguity of the question the decision-maker must answer, 3. the scale used to measure the intensity of preferences, and 4. the principle of hierarchical composition and rank reversal. Perez (1995) also focused on criteria weights and the rank reversal phenomenon. The author argued that this undesirable effect does 
not, per se, invalidate the AHP, but it does make it necessary to identify the kind of situations in which the method is suitable. Dyer (1990) also argued that the AHP is flawed as a procedure for ranking alternatives in that the rankings obtained by this method are arbitrary. This paper further focused on the operational difficulty encountered by the AHP.

The proposed methodology provides a robust Decision Support System (DSS) that is developed based on the linguistic judgment of managers. Humans employ mostly words in computing and reasoning (Zadeh, 1996) and therefore the proposed method makes the classification problem more accurate and easy to understand and apply. Here are the features of the proposed method in general:

1. It mimics the ability of the human mind to effectively employ modes of reasoning (Zadeh, 1994);

2. It is constructed based on the managers' natural language and therefore more acceptable and understandable to inventory managers;

3. It is capable to consider a large number of criteria to classify a large number of SKUs;

4. It is capable to classify the SKUs to the desired number of classes;

5. The results are not considerably changed due to a few changes in rules.

The proposed methodology has, however, some disadvantages. For example aggregating the rules from different experts is sometimes difficult when these experts do not agree on a specific output of a rule.

\section{Conclusion and future research directions}

In this paper using fuzzy logic, we constructed a rule-based inference system for classifying inventories into different classes according to their multi-criteria importance. While the traditional inventory classification considers only one criterion (annual dollar usage) and classifies items into only three classes, the proposed method in this paper considers several criteria for its classification. The proposed method also has an ability to classify items to more than three classes. Implementation of this method in real world situations is simple and easier to understand by inventory managers because it is constructed based on the natural language. We also used the AHP for comparison purposes and discussed the advantages and disadvantages of the proposed method.

Here are some suggestions and ideas for future works:

In this paper, we implemented our method based on a set of crisp data of 54 SKUs from a real case study. This was made possible because our four criteria were measureable 
quantitatively. However collecting the relevant data, in a crisp format in some real world situations where qualitative criteria have to be considered as well, is difficult. For example, in some real world situations, managers prefer to use linguistic values such as 'low' or 'very high' for a qualitative criterion such as 'critical'. Linguistic values of linguistic variables are usually embodied by fuzzy numbers. In this situation the proposed methodology is not suitable. Instead, we suggest exploring the proposed method by using data as input of the system that are not accessible and/or measurable in crisp format. The suggested method would then work with fuzzy input (instead of crisp input).

In the literature of inventory classification (both traditional and multi-criteria approaches), SKUs are classified into different classes according to their importance. The importance of items is defined based on the managers' point of view of the firms; while nowadays most firms make most of their decisions in supply chains. Supply Chain Management (SCM) is the management of materials and information which flow both in and between facilities such as vendors, manufacturing and assembly plants, and distribution centers (Thomas and Griffin, 1996). Therefore, we suggest considering the impact of these relationships in supply chain management on inventory classification. For instance we can consider the impact of information sharing in SCM on inventory classification. Information sharing can reduce ordering costs, inventory costs, and supply lead times (Seidmann and Sundararajan, 1997). Therefore, it is clear that the importance of items with long lead time will diminish and these items will be moved from their classes to less important classes. As an example, joint planning in the SCM can lead to the 'integrated importance' for inventories across the supply chain.

And finally, while all methods of $\mathrm{ABC}$ classification have been proposed in multi-criteria framework, we believe that inventory classification should be considered as a multi-objective problem. For example we have to take into account the objectives of carrying inventories as outlined by Dowlatshahi (2007):

- To meet variations (fluctuations) in demand

- To hedge against inflation or sudden increases in price

- To allow flexibility for product and operational scheduling

- To maintain independence of operation

- To provide a safeguard against delivery problems (e.g. supplier strike, weather conditions, custom delays)

- To take advantage of quantity discounts. 
Considering these objectives, we are also able to determine the 'optimal' solution for the problem, which does not depend on the managers' 'judgment'. This optimal solution can be used as a benchmark to compare the MCIC methods.

\section{Acknowledgement}

The authors are grateful to Prof. C. Whybark (co-author of the first paper in multi-criteria $\mathrm{ABC}$ classification) and anonymous referees for their constructive criticism of the initial version of this paper.

\section{References}

Bhattacharya A, Sarkar B, Mukherjee S.K. Distance-based consensus method for ABC analysis. International Journal of Production Research 2007; 45(15): 3405-3420.

Cakir O, Canbolat M.S. A web-based decision support system for multi-criteria inventory classification using fuzzy AHP methodology. Expert Systems with Applications 2008; 35:1367-1378.

Chen Y, Li K.W, Kilgour D.M, Hipel K.W. A case-based distance model for multiple criteria ABC analysis. Computers \& Operations Research 2008; 35: 776-796.

Chu C.W, Liang G.S, Liao C.T. Controlling inventory by combining ABC analysis and fuzzy classification. Computers \& Industrial Engineering 2008; 55: 841-851.

Cohen M.A, Ernst R. Multi-item classification and generic inventory stock control policies. Production and Inventory Management Journal 1988; 29(3): 6-8.

Dowlatshahi S. Production/Operations Management. Second edition, Copley Publishing Company, 2007.

Dyer J. S. Remarks on the analytic hierarchy process. Management Science 1990; 36(3): 249-258.

Flores B.E, Olson D.L, Dorai V. K. Management of multi-criteria inventory classification. Mathematical and Computer Modeling 1992; 16(12): 71-82.

Flores B.E, Whybark D.C. Implementing multiple criteria ABC analysis. Journal of Operations Management 1987; 7(1) 79-84.

Flores B.E, Whybark D.C. Multiple criteria ABC analysis. International Journal of Operations and Production Management 1986; 6(3): 38-46.

Guvenir H.A, Erel E. Multi-criteria inventory classification using genetic algorithm. European Journal of Operational Research 1998; 105(1): 29-37.

Harker P.T, Vargas L.G. The theory of ratio scale estimation: Saaty's Analytic Hierarchy Process. Management Science 1987; 33(11): 1383-1403. 
Jang J.S.R, Gulley N. The Fuzzy Logic Toolbox for Use with MATLAB. Natick, MA: The Mathworks, Inc., 1995.

Jang J.S.R. ANFIS: Adaptive-Network-Based Fuzzy Inference System. IEEE Transactions on Systems, Man and Cybernetics 1993; 23(3): 665-685.

Mamadani E.H, Assilian S. An experiment in linguistic synthesis with a fuzzy logic controller. International Journal of Man-Machine Studies 1975; 7: 1-13.

Martin W, Stanford R.E. A methodology for estimating the maximum profitable turns for an ABC inventory classification system. IMA Journal of Management Mathematics 2007; 18: 223-233.

Partovi F.Y, Anandarajan M. Classifying inventory using an artificial neural network approach. Computer and Industrial Engineering 2002; 41: 389-404.

Partovi F.Y, Burton J. Using the analytic hierarchy process for ABC analysis. International Journal of Production and Operations Management 1993; 13(9) 29-44.

Perez J. Some comments on Saaty’s AHP. Management Science 1995; 41(6): 1091-1095.

Puente J, de la Fuente D, Priore P, Pino R. ABC Classification with uncertain data: a fuzzy model vs. a probabilistic model. Applied Artificial Intelligence 2002; 16(6): 443-456.

Ramanathan R. ABC inventory classification with multiple-criteria using weighted linear optimization. Computers \& Operations Research 2006; 33(3): 695-700.

Reynolds M.P. Spare Parts Inventory Management. APICS-the performance advantage 1994: 42-46.

Rezaei J. A fuzzy model for multi-criteria inventory classification. $6^{\text {th }}$ International Conference on Analysis of Manufacturing Systems. AMS 2007, Lunteren, The Netherlands, May 2007.

Saaty T.L. Decision-making for Leaders; The Analytical Hierarchy Process for Decisions in a Complex World, Belmont, CA: Wadsworth, 1982.

Seidmann A, Sundararajan A. Building and sustaining inter organizational information sharing relationships: the competitive impact of interfacing supply chain operations with marketing strategy, Proceedings of the eighteenth international conference on Information systems, Atlanta, Georgia, United States, p. 205-222, 1997.

Setnes M, Babuska R, Kaymak U, van Nauta Lemke H.R. Similarity measures in fuzzy rule base simplification. IEEE Transactions on Systems, Man and Cybernetics, Part B 1998; 28(3):376-386.

The MathWorks, http://www.mathworks.com.

Thomas D. J, Griffin P. M. Coordinated supply chain management. European Journal of Operational Research 1996; 94: 1-15.

Vollmann T. E, Berry W. L, Whybark D.C. Manufacturing Planning and Control Systems, fourth edition, McGraw-Hill, Boston, 1997.

Yam Y, Baranyi P, Yang C.T. Reduction of fuzzy rule base via singular value decomposition. IEEE Transaction on Fuzzy Systems 1999; 7: 120-132. 
Yen J, Langari R. Fuzzy Logic Intelligence, Control, and Information. Prentice Hall Publishing Company 1999.

Zadeh L.A. Fuzzy logic = computing with words. IEEE Transactions on Fuzzy Systems 1996; 4(2): 103111.

Zadeh L.A. Fuzzy logic, neural networks, and soft computing. Communications of the ACM 1994; 37(3):77-84.

Zadeh L.A. Fuzzy sets. Information and Control 1965; 8: 338-353.

Zadeh L.A. The role of fuzzy logic in the management of uncertainty in expert systems. Fuzzy Sets and Systems, vol. 11, pp. 199-227, 1983.

Zhou P, Fan L. A note on multi-criteria ABC inventory classification using weighted linear optimization. European Journal of Operational Research 2007; 182: 1488-1491. 
Table 1 Multi-criteria ABC inventory classification methods

\begin{tabular}{|c|c|c|}
\hline Author(s) & Methodology & Description \\
\hline $\begin{array}{l}\text { Flores and Whybark, } \\
\text { (1986 and 1987) }\end{array}$ & Joint Criteria Matrix & $\begin{array}{l}\text { The 'multi-criteria' concept of ABC inventory classification is } \\
\text { introduced by using this method for the first time. However the } \\
\text { proposed methodology is a bi-criteria rather than multi-criteria } \\
\text { method. }\end{array}$ \\
\hline $\begin{array}{l}\text { Cohen and Ernst } \\
\text { (1988) }\end{array}$ & Cluster Analysis & $\begin{array}{l}\text { By using Cluster Analysis, SKUs are clustered into different } \\
\text { groups based on different criteria. This method can consider a } \\
\text { large number of criteria. However it is too sophisticated and is } \\
\text { also vulnerable to the introduction of new criteria. }\end{array}$ \\
\hline $\begin{array}{l}\text { Flores et al. (1992) } \\
\text { and Partovi and } \\
\text { Burton (1993) }\end{array}$ & $\begin{array}{l}\text { Analytic Hierarchy } \\
\text { Process (AHP) }\end{array}$ & $\begin{array}{l}\text { This methodology is able to classify SKUs into different } \\
\text { number of classes using different criteria. However it is } \\
\text { vulnerable to the number of criteria used. }\end{array}$ \\
\hline Reynolds (1994) & Heuristic & This method is only appropriate for process industries. \\
\hline $\begin{array}{l}\text { Guvenir and Erel } \\
\text { (1998) }\end{array}$ & $\begin{array}{l}\text { AHP and Genetic } \\
\text { Algorithm (GA) }\end{array}$ & $\begin{array}{l}\text { The AHP classification method has most of the advantages and } \\
\text { disadvantages of AHP. Here GA is used to learn the weight } \\
\text { vector along with the cut-off values for multi-criteria inventory } \\
\text { classification. }\end{array}$ \\
\hline Puente et al. (2002) & Fuzzy Set Theory & $\begin{array}{l}\text { This method considers the predicted criteria as fuzzy numbers. } \\
\text { Although this method is a bi-criteria method it can be extended } \\
\text { to multi-criteria approach. }\end{array}$ \\
\hline $\begin{array}{l}\text { Partovi and } \\
\text { Anandarajan (2002) }\end{array}$ & $\begin{array}{l}\text { Aartificial Nneural } \\
\text { Nnetwork (ANN) }\end{array}$ & $\begin{array}{l}\text { Two learning methods have been used in this approach: back } \\
\text { propagation and genetic algorithm. This method is largely } \\
\text { dependent on the data set used for learning. }\end{array}$ \\
\hline $\begin{array}{l}\text { Ramanathan (2006); } \\
\text { Zhou and Fan (2007) }\end{array}$ & $\begin{array}{l}\text { Weighted Linear } \\
\text { Optimization }\end{array}$ & $\begin{array}{l}\text { This method is a Data Envelopment Analysis method, which } \\
\text { ranks SKUs based on their optimal scores. This method does } \\
\text { not utilize the specialist knowledge to determine the criteria } \\
\text { weights. }\end{array}$ \\
\hline $\begin{array}{l}\text { Rezaei (2007); Cakir } \\
\text { and Canbolat (2008) }\end{array}$ & $\begin{array}{l}\text { Fuzzy Analytic } \\
\text { Hierarchy Process } \\
\text { (FAHP) }\end{array}$ & $\begin{array}{l}\text { For comparison of the criteria, this method uses fuzzy numbers } \\
\text { instead of crisp numbers. This method is able to classify the } \\
\text { SKUs to different number of classes. }\end{array}$ \\
\hline $\begin{array}{l}\text { Bhattacharya et al. } \\
\text { (2007) }\end{array}$ & $\begin{array}{l}\text { Technique for Order } \\
\text { Preferences by } \\
\text { Similarity to the Ideal } \\
\text { Solution (TOPSIS) }\end{array}$ & $\begin{array}{l}\text { By using experts' knowledge, this method ranks SKUs and } \\
\text { classifies them into different groups. This method has some of } \\
\text { the disadvantages of AHP as it uses the pair-wise comparisons } \\
\text { of criteria. }\end{array}$ \\
\hline Chu et al. (2008) & $\begin{array}{l}\text { Fuzzy Classification } \\
\text { Analysis }\end{array}$ & $\begin{array}{l}\text { This method uses fuzzy classification analysis to classify SKUs } \\
\text { into three classes. This method is able to apply both nominal } \\
\text { and non-nominal criteria and attributes. Using this method to } \\
\text { classify SKUs to more than three classes is very difficult. }\end{array}$ \\
\hline Chen $e t$ & Case-based & $\begin{array}{l}\text { This method is dependent on the data set. It has complicated } \\
\text { phases and classifies SKUs to only three classes. }\end{array}$ \\
\hline
\end{tabular}


1

2

3

4

5

6

7

8

9

10

11

12

13

14

15

16

17

18

19

20

21

22

23

24

25

26

27

28

29

30

31

32

33

34

35

36

37

38

39

40

41

42

43

44

45

46

47

48

49

50

51

52

53

54

55

56

57

58

59

60
Table 2 Fuzzy rule base for four inputs comprising of 81 antecedent-consequent pairs

\begin{tabular}{|c|c|c|c|c|c|}
\hline \multirow[t]{2}{*}{ Rule No } & \multicolumn{4}{|c|}{ Fuzzy rule base input } & \multirow{2}{*}{$\begin{array}{c}\begin{array}{c}\text { Fuzzy rule } \\
\text { base output }\end{array} \\
\text { Item Class }\end{array}$} \\
\hline & UP & $\mathrm{AD}$ & LT & DU & \\
\hline 1 & $\mathrm{~L}$ & $\mathrm{~L}$ & $\mathrm{~L}$ & $\mathrm{~L}$ & $\mathrm{~L}$ \\
\hline$\cdot$ & $\cdot$ & . & . & $\cdot$ & $\cdot$ \\
\hline . & : & . & : & $\dot{.}$ & . \\
\hline 39 & $\dot{M}$ & M & L & $\dot{\mathrm{H}}$ & $\dot{H}$ \\
\hline 40 & $\mathrm{M}$ & $\mathrm{M}$ & $\mathrm{M}$ & $\mathrm{L}$ & M \\
\hline . & i & : & : & . & . \\
\hline$\dot{81}$ & $\dot{\mathrm{H}}$ & $\mathrm{H}$ & $\dot{\mathrm{H}}$ & $\dot{\mathrm{H}}$ & $\dot{\mathrm{H}}$ \\
\hline
\end{tabular}


Appendix I

Table 3. The normalized measures and defuzzified scores of the inventory criteria measures

\begin{tabular}{|c|c|c|c|c|c|c|c|c|c|c|}
\hline \multirow[b]{2}{*}{$\begin{array}{l}\text { Item } \\
\text { No. }\end{array}$} & \multirow[b]{2}{*}{$\begin{array}{c}\text { Unit } \\
\text { price }(€)\end{array}$} & \multirow[b]{2}{*}{$\begin{array}{l}\text { Annual } \\
\text { demand }\end{array}$} & \multirow{2}{*}{$\begin{array}{l}\text { Lead } \\
\text { time } \\
\text { (day) }\end{array}$} & \multirow[b]{2}{*}{$\begin{array}{c}\text { Durability } \\
\text { (month) }\end{array}$} & \multicolumn{4}{|c|}{ Normalized measures } & \multirow{2}{*}{$\begin{array}{l}\text { AHP } \\
\text { score }\end{array}$} & \multirow{2}{*}{$\begin{array}{l}\text { Deffuzzified } \\
\text { score }\end{array}$} \\
\hline & & & & & $\begin{array}{l}\text { Unit } \\
\text { price }\end{array}$ & $\begin{array}{l}\text { Annual } \\
\text { demand }\end{array}$ & $\begin{array}{c}\text { Lead } \\
\text { time }\end{array}$ & Durability & & \\
\hline S1 & 14 & 2500 & 4 & 6 & 0.387 & 0.548 & 0.5 & 0.706 & 0.580 & 0.553 \\
\hline S2 & 2.2 & 2750 & 1 & 2 & 0.006 & 0.604 & 0 & 0.941 & 0.604 & 0.862 \\
\hline S3 & 8.5 & 350 & 1 & 12 & 0.21 & 0.061 & 0 & 0.353 & 0.191 & 0.155 \\
\hline S4 & 26 & 3200 & 2 & 3 & 0.774 & 0.706 & 0.167 & 0.882 & 0.753 & 0.775 \\
\hline S5 & 6.7 & 850 & 1 & 6 & 0.152 & 0.174 & 0 & 0.706 & 0.362 & 0.411 \\
\hline S6 & 2 & 1200 & 1 & 1 & 0 & 0.253 & 0 & 1 & 0.481 & 0.592 \\
\hline S7 & 16 & 500 & 3 & 12 & 0.452 & 0.095 & 0.333 & 0.353 & 0.261 & 0.471 \\
\hline S8 & 25 & 750 & 2 & 6 & 0.742 & 0.152 & 0.167 & 0.706 & 0.454 & 0.466 \\
\hline S9 & 11.5 & 2270 & 3 & 12 & 0.306 & 0.495 & 0.333 & 0.353 & 0.403 & 0.479 \\
\hline $\mathrm{S} 10$ & 4.5 & 850 & 1 & 12 & 0.081 & 0.174 & 0 & 0.353 & 0.217 & 0.315 \\
\hline $\mathrm{S} 11$ & 13 & 570 & 2 & 3 & 0.355 & 0.111 & 0.167 & 0.882 & 0.443 & 0.522 \\
\hline $\mathrm{S} 12$ & 15 & 660 & 2 & 8 & 0.419 & 0.131 & 0.167 & 0.588 & 0.351 & 0.303 \\
\hline S13 & 15 & 2150 & 3 & 2 & 0.419 & 0.468 & 0.333 & 0.941 & 0.632 & 0.853 \\
\hline S14 & 3.1 & 360 & 2 & 8 & 0.035 & 0.063 & 0.167 & 0.588 & 0.263 & 0.147 \\
\hline S15 & 3.5 & 860 & 1 & 1 & 0.048 & 0.176 & 0 & 1 & 0.457 & 0.534 \\
\hline S16 & 5 & 3350 & 2 & 1 & 0.097 & 0.74 & 0.167 & 1 & 0.705 & 0.839 \\
\hline S17 & 33 & 480 & 2 & 12 & 1 & 0.09 & 0.167 & 0.353 & 0.336 & 0.481 \\
\hline $\mathrm{S} 18$ & 9.5 & 900 & 1 & 6 & 0.242 & 0.186 & 0 & 0.706 & 0.380 & 0.442 \\
\hline S19 & 6 & 1100 & 3 & 3 & 0.129 & 0.231 & 0.333 & 0.882 & 0.466 & 0.564 \\
\hline $\mathrm{S} 20$ & 8.5 & 650 & 3 & 3 & 0.21 & 0.129 & 0.333 & 0.882 & 0.437 & 0.548 \\
\hline $\mathrm{S} 21$ & 9 & 580 & 3 & 3 & 0.226 & 0.113 & 0.333 & 0.882 & 0.433 & 0.56 \\
\hline $\mathrm{S} 22$ & 12 & 4500 & 4 & 6 & 0.323 & 1 & 0.5 & 0.706 & 0.755 & 0.667 \\
\hline $\mathrm{S} 23$ & 7.5 & 1280 & 1 & 3 & 0.177 & 0.271 & 0 & 0.882 & 0.472 & 0.601 \\
\hline $\mathrm{S} 24$ & 13 & 880 & 2 & 12 & 0.355 & 0.181 & 0.167 & 0.353 & 0.272 & 0.327 \\
\hline $\mathrm{S} 25$ & 17 & 1470 & 2 & 8 & 0.484 & 0.314 & 0.167 & 0.588 & 0.436 & 0.46 \\
\hline S26 & 2.5 & 1120 & 2 & 9 & 0.016 & 0.235 & 0.167 & 0.529 & 0.308 & 0.396 \\
\hline S27 & 2.8 & 860 & 4 & 6 & 0.026 & 0.176 & 0.5 & 0.706 & 0.371 & 0.412 \\
\hline $\mathrm{S} 28$ & 7.5 & 2600 & 1 & 1 & 0.177 & 0.57 & 0 & 1 & 0.639 & 0.851 \\
\hline S29 & 8.5 & 950 & 5 & 1 & 0.21 & 0.197 & 0.667 & 1 & 0.528 & 0.556 \\
\hline S30 & 23 & 670 & 2 & 2 & 0.677 & 0.133 & 0.167 & 0.941 & 0.525 & 0.529 \\
\hline S31 & 15 & 760 & 3 & 6 & 0.419 & 0.154 & 0.333 & 0.706 & 0.414 & 0.521 \\
\hline S32 & 11.5 & 890 & 1 & 8 & 0.306 & 0.183 & 0 & 0.588 & 0.345 & 0.335 \\
\hline S33 & 12 & 4500 & 2 & 12 & 0.323 & 1 & 0.167 & 0.353 & 0.603 & 0.51 \\
\hline S34 & 11 & 250 & 4 & 3 & 0.29 & 0.038 & 0.5 & 0.882 & 0.422 & 0.622 \\
\hline S35 & 8.5 & 870 & 1 & 2 & 0.21 & 0.179 & 0 & 0.941 & 0.461 & 0.539 \\
\hline S36 & 15 & 1350 & 2 & 1 & 0.419 & 0.287 & 0.167 & 1 & 0.570 & 0.629 \\
\hline S37 & 4.7 & 740 & 6 & 12 & 0.087 & 0.149 & 0.833 & 0.353 & 0.255 & 0.275 \\
\hline S38 & 8.6 & 170 & 3 & 12 & 0.213 & 0.02 & 0.333 & 0.353 & 0.193 & 0.371 \\
\hline S39 & 7.4 & 220 & 2 & 6 & 0.174 & 0.032 & 0.167 & 0.706 & 0.316 & 0.406 \\
\hline S40 & 6.5 & 750 & 5 & 2 & 0.145 & 0.152 & 0.667 & 0.941 & 0.477 & 0.522 \\
\hline S41 & 16 & 150 & 4 & 8 & 0.452 & 0.016 & 0.5 & 0.588 & 0.327 & 0.5 \\
\hline S42 & 11 & 650 & 1 & 12 & 0.29 & 0.129 & 0 & 0.353 & 0.232 & 0.25 \\
\hline S43 & 3.6 & 270 & 3 & 9 & 0.052 & 0.043 & 0.333 & 0.529 & 0.244 & 0.147 \\
\hline S44 & 8.3 & 470 & 1 & 18 & 0.203 & 0.088 & 0 & 0 & 0.068 & 0.154 \\
\hline S45 & 5.5 & 860 & 1 & 6 & 0.113 & 0.176 & 0 & 0.706 & 0.356 & 0.412 \\
\hline S46 & 7.5 & 80 & 4 & 8 & 0.177 & 0 & 0.5 & 0.588 & 0.278 & 0.32 \\
\hline S47 & 9.5 & 140 & 3 & 3 & 0.242 & 0.014 & 0.333 & 0.882 & 0.395 & 0.573 \\
\hline S48 & 13 & 1240 & 2 & 3 & 0.355 & 0.262 & 0.167 & 0.882 & 0.505 & 0.592 \\
\hline S49 & 9.5 & 660 & 3 & 1 & 0.242 & 0.131 & 0.333 & 1 & 0.488 & 0.582 \\
\hline S50 & 27 & 560 & 7 & 1 & 0.806 & 0.109 & 1 & 1 & 0.604 & 0.848 \\
\hline S51 & 3.8 & 380 & 1 & 6 & 0.058 & 0.068 & 0 & 0.706 & 0.303 & 0.362 \\
\hline S52 & 16 & 860 & 2 & 12 & 0.452 & 0.176 & 0.167 & 0.353 & 0.286 & 0.318 \\
\hline S53 & 15 & 1250 & 5 & 8 & 0.419 & 0.265 & 0.667 & 0.588 & 0.433 & 0.5 \\
\hline S54 & 9.2 & 340 & 3 & 3 & 0.232 & 0.059 & 0.333 & 0.882 & 0.412 & 0.565 \\
\hline
\end{tabular}


Table 4. Final classification results of the proposed method and the AHP

\begin{tabular}{|c|c|c|c|}
\hline $\begin{array}{l}\text { Item } \\
\text { No. }\end{array}$ & $\begin{array}{c}\text { Descending order } \\
\text { of defuzzified values }\end{array}$ & $\begin{array}{l}\text { Fuzzy Logic } \\
\text { classification }\end{array}$ & $\begin{array}{c}\text { AHP } \\
\text { classification } \\
\end{array}$ \\
\hline S2 & 0.862 & $\overline{\mathrm{A}}$ & $\overline{\mathrm{A}}$ \\
\hline $\mathrm{S} 13$ & 0.853 & A & A \\
\hline S28 & 0.851 & A & A \\
\hline S50 & 0.848 & A & A \\
\hline S16 & 0.839 & A & A \\
\hline S4 & 0.775 & A & A \\
\hline S22 & 0.667 & A & A \\
\hline S36 & 0.629 & A & B \\
\hline S34 & 0.622 & A & C \\
\hline S23 & 0.601 & B & B \\
\hline S6 & 0.592 & B & B \\
\hline S48 & 0.592 & B & B \\
\hline S49 & 0.582 & B & B \\
\hline S47 & 0.573 & B & C \\
\hline S54 & 0.565 & B & $\mathrm{C}$ \\
\hline S19 & 0.564 & B & B \\
\hline S21 & 0.56 & B & C \\
\hline S29 & 0.556 & B & B \\
\hline $\mathrm{S} 1$ & 0.553 & B & A \\
\hline S20 & 0.548 & B & B \\
\hline S35 & 0.539 & B & B \\
\hline S15 & 0.534 & B & B \\
\hline S30 & 0.529 & B & B \\
\hline S11 & 0.522 & B & B \\
\hline S40 & 0.522 & C & B \\
\hline S31 & 0.521 & C & C \\
\hline S33 & 0.51 & C & A \\
\hline S41 & 0.5 & $\mathrm{C}$ & $\mathrm{C}$ \\
\hline S53 & 0.5 & $\mathrm{C}$ & $\mathrm{C}$ \\
\hline S17 & 0.481 & C & C \\
\hline S9 & 0.479 & C & C \\
\hline S7 & 0.471 & C & C \\
\hline S8 & 0.466 & $\mathrm{C}$ & B \\
\hline S25 & 0.46 & $\mathrm{C}$ & B \\
\hline $\mathrm{S} 18$ & 0.442 & $\mathrm{C}$ & $\mathrm{C}$ \\
\hline S27 & 0.412 & C & C \\
\hline S45 & 0.412 & C & C \\
\hline S5 & 0.411 & C & C \\
\hline S39 & 0.406 & C & C \\
\hline S26 & 0.396 & $\mathrm{C}$ & $\mathrm{C}$ \\
\hline S38 & 0.371 & $\mathrm{C}$ & $\mathrm{C}$ \\
\hline S51 & 0.362 & $\mathrm{C}$ & C \\
\hline S32 & 0.335 & C & C \\
\hline S24 & 0.327 & C & C \\
\hline S46 & 0.32 & $\mathrm{C}$ & $\mathrm{C}$ \\
\hline S52 & 0.318 & $\mathrm{C}$ & $\mathrm{C}$ \\
\hline S10 & 0.315 & $\mathrm{C}$ & $\mathrm{C}$ \\
\hline $\mathrm{S} 12$ & 0.303 & C & C \\
\hline S37 & 0.275 & C & C \\
\hline S42 & 0.25 & C & C \\
\hline S3 & 0.155 & C & C \\
\hline S44 & 0.154 & $\mathrm{C}$ & C \\
\hline S14 & 0.147 & $\mathrm{C}$ & $\mathrm{C}$ \\
\hline S43 & 0.147 & $\mathrm{C}$ & $\mathrm{C}$ \\
\hline
\end{tabular}


Table 5. Comparison of the proposed method and AHP

\begin{tabular}{cccccc}
\hline & \multicolumn{5}{c}{ AHP } \\
\cline { 2 - 6 } & & A & B & C & Total \\
\cline { 2 - 6 } & A & 7 & 1 & 1 & $\mathbf{9}$ \\
Proposed & B & 1 & 11 & 3 & $\mathbf{1 5}$ \\
method & C & 1 & 3 & 26 & $\mathbf{3 0}$ \\
& Total & $\mathbf{9}$ & $\mathbf{1 5}$ & $\mathbf{3 0}$ & $\mathbf{5 4}$ \\
\hline
\end{tabular}




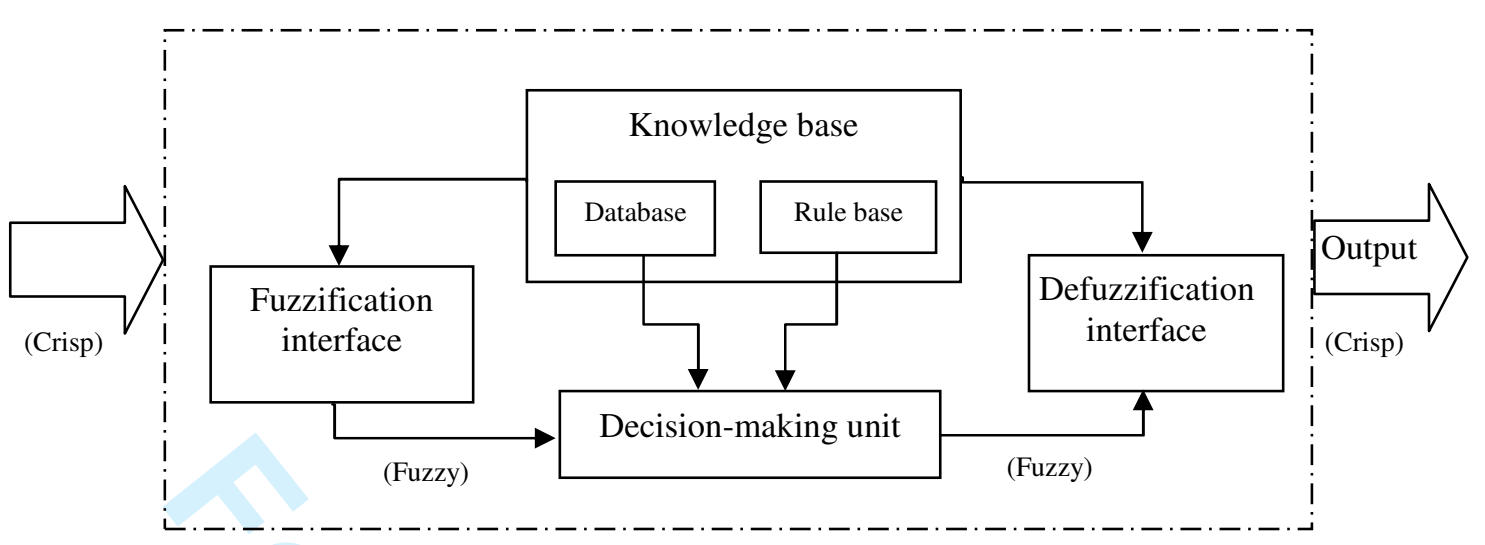

Figure 1 Fuzzy Inference System 


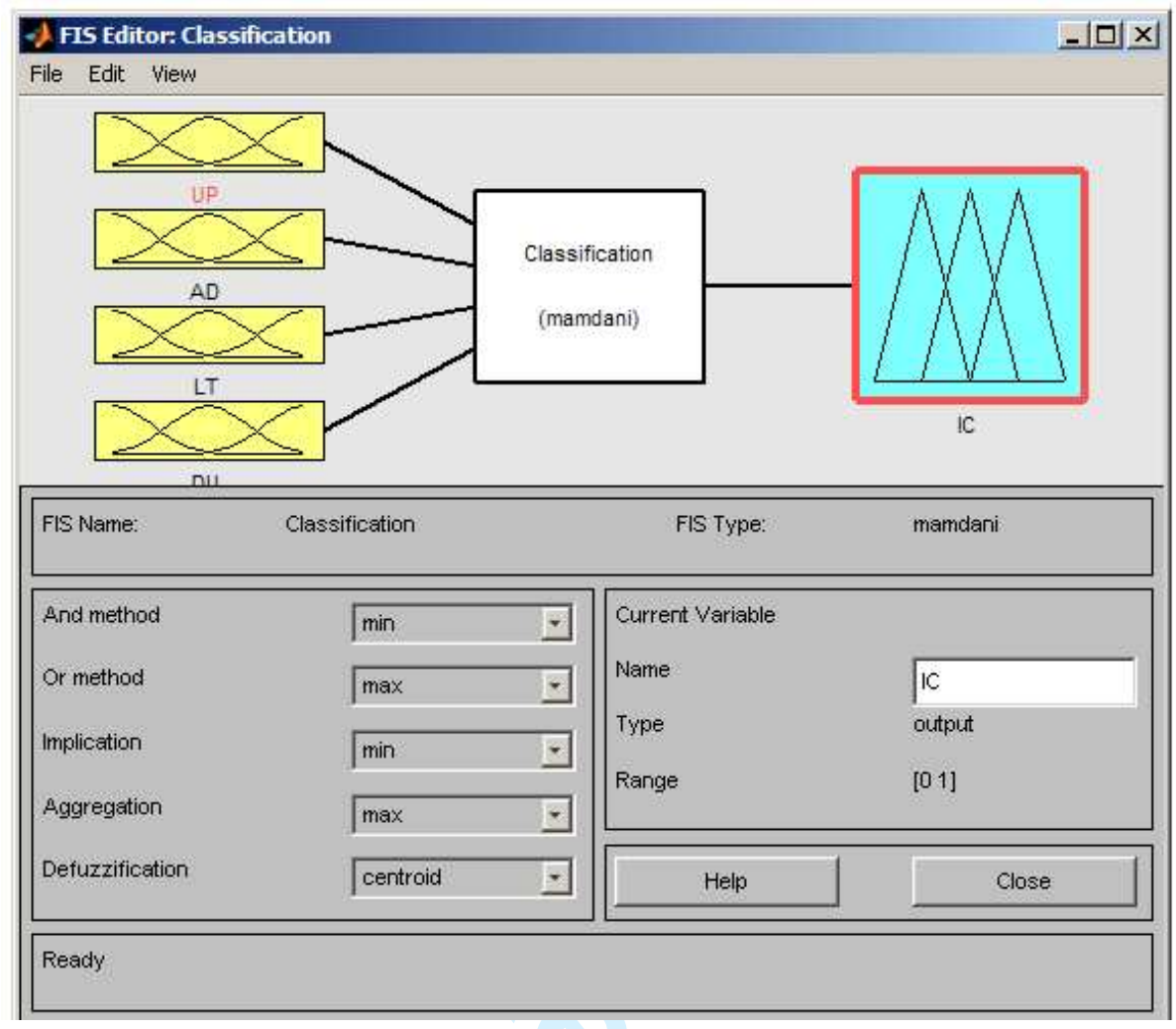

Figure 2 The intended fuzzy inference system 


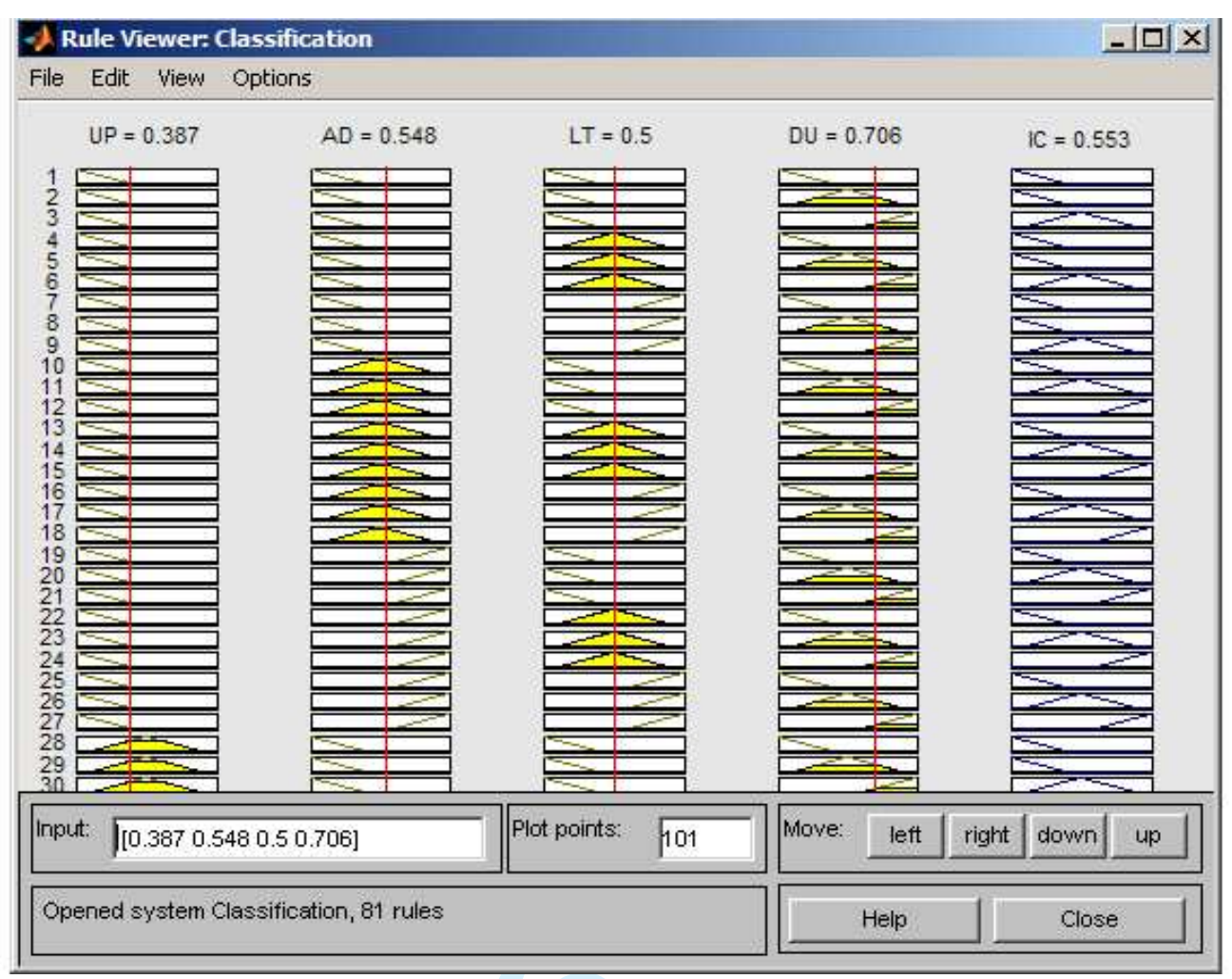

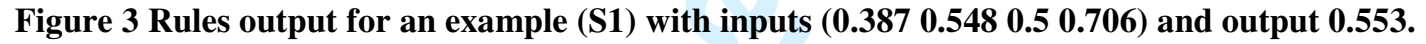

